\title{
Urdimento
}

Revista de Estudos em Artes Cênicas

E-ISSN: 2358.6958

\section{A visão encarnada do espectador: Formas de perceber, habitar e criar paisagens}

\author{
Laila Renardini Padovan
}

\section{Para citar este artigo:}

PADOVAN, Laila Renardini. A visão encarnada do espectador: Formas de perceber, habitar e criar paisagens. Urdimento, Florianópolis, v. 2, n. 38, ago./set. 2020.

DOI: http:/dx.doi.org/10.5965/14145731023820200016

Este artigo passou pelo Plagiarism Detection Software | iThenticate 
A visão encarnada do espectador: Formas de perceber, habitar e criar paisagens

\author{
Laila Renardini Padovan ${ }^{1}$
}

\begin{abstract}
Resumo
Este trabalho teve como ponto de partida a problematização da relação entre corpo e espaço presente na dança realizada em salas de ensaio e em teatros italianos, questionando as ideias de um espaço neutro para o bailarino e de um único ponto de vista ideal para o espectador, e reconhecendo as relações de poder inerentes a essas espacialidades. A partir da reflexão sobre as criações em dança contextuais do projeto Corpo e Paisagem, defendeu-se a importância de práticas artísticas de posicionamento realizadas a partir de saberes localizados e de uma visão encarnada e contextualizada, para então rever os papéis do artista e do espectador e suas relações contemplativas e compositivas com a paisagem e com a obra artística.
\end{abstract}

Palavras-chave: Visão encarnada. Dança Contextual. Espectador. Paisagem.

The embodied view of the spectator: Ways to perceive, inhabit and create landscapes

\begin{abstract}
The theater building builds professional and human relationships, which develop a unique transit between this building and the city that houses it. This perspective provided a unique concept of Scenography. The theoretical foundation is centered on the epistemological study that Michel Foucault undertook, recognizing in the 16th century the cognitive action of "spatializing knowledge", which connects the microcosm to the macrocosm. This cognitive "spatialization" will be considered according to the physical and virtual spaces. The virtual will be analyzed using the digital platform, which allows theatrical performances and audiences to be found in streets and squares recreating the containment rules.
\end{abstract}

Keywords: Theater Building. City. Physical Space. Virtual Space.

Doutoranda em Artes da Cena no Instituto de Artes da UNICAMP (Universidade Estadual de Campinas). Artista da dança independente, desenvolve criações contextuais em paisagens urbanas e da natureza, investigando novas formas de relação entre artista e espectador. É integrante da Cia. Damas em Trânsito e os Bucaneiros. Lailapadovan@yahoo.com 
La vista encarnada del espectador: Formas de percibir, habitar y crear paisajes

\section{Resumen}

Este trabajo tuvo como punto de partida la problematización de la relación entre el cuerpo y el espacio presente en la danza realizada en salas de ensayo y en teatros italianos, cuestionando las ideas de un espacio neutral para el bailarín y de un único punto de vista ideal para el espectador, y reconociendo las relaciones de poder inherentes a estas espacialidades. Sobre la base de la reflexión a cerca de las creaciones de danza contextual del proyecto Corpo e Paisagem, se defendió la importancia de las prácticas artísticas de posicionamiento basadas en el conocimiento localizado y una visión encarnada y contextualizada, para luego revisar los roles del artista y el espectador. y sus relaciones contemplativas y compositivas con el paisaje y el trabajo artístico.

Palabras-clave: Vista encarnada. Danza Contextual. Espectador. Paisaje. 
Este presente trabalho pretende refletir sobre parte de minha prática artística no projeto autoral Corpo e Paisagem, que venho realizando desde 2018 e que, até a presente data, já foi realizado em duas versões diferentes: a primeira, em 2018, no CRD (Centro de Referência da Dança); e a segunda, em 2019, no CCSP (Centro Cultural São Paulo). ${ }^{2}$ As duas versões do projeto Corpo e Paisagem propuseram, através de suas práticas performativas, refletir sobre alguns modos de relação entre corpo-paisagem e sobre como foi possível perceber, habitar e criar paisagens através de encontros e deslocamentos entre artista e espectador. As criações e experimentações em dança foram desenvolvidas a partir do contexto em que se inseriam, em uma relação estreita entre o corpo e as paisagens cotidianas por ele habitadas.

A primeira versão do Projeto Corpo e Paisagem se deu em 2018 como uma proposta de curso, dentro do CRD (Centro de Referência da Dança) em São Paulo, com aproximadamente 35 inscritos, que abordava a criação em dança que se dá em, com e para as paisagens urbanas do entorno do CRD, localizado no centro antigo de São Paulo. O projeto trabalhou: a sensibilização dos sentidos do corpo (olfato, visão, audição, tato, etc.) na percepção da cidade, o ato de caminhar como prática estética (derivas), e relações lúdicas e poéticas com o espaço; sendo que, ao final do curso, os participantes criaram coletivamente Intervenções Cênicas nos arredores do CRD. O curso durou 1 semestre e funcionou como um Grupo de Investigação sobre o encontro corpo-cidade, trazendo à tona conflitos, questionamentos e poéticas que vivemos cotidianamente na nossa relação corporal com São Paulo.

A segunda versão do Projeto Corpo e Paisagem ocorreu em 2019, através do apoio do Edital de Mediação em Arte e Cidadania Cultural, no Centro Cultural São Paulo (CCSP). Quatro temáticas foram focadas na relação corporal com as diversas paisagens do CCSP: 1) Subjetividade e Intimidade; 2) Sensorialidade; 3) Temporalidades; 4) Encontro, Coletividade e Celebração. Para cada temática, 
foram abertas inscrições (em média com 25 participantes cada), formando um grupo de trabalho e investigação de cada tema. Cada grupo trabalhou conjuntamente por 1 mês e meio, com a minha orientação, realizando experimentações nos diversos espaços do CCSP, e, ao final desse tempo, criou coletivamente uma Intervenção Artística que foi compartilhada com o público. Sendo assim, a cada 1 mês e meio de projeto foi criada uma intervenção, totalizando ao final: 6 meses de projeto continuado e 4 Intervenções diferentes em paisagens diversas do CCSP, sendo elas: À Beira de Si, Escuro; Temporã; e Concreto Veraneio.

\section{O Espaço Cênico da Dança}

O Projeto Corpo e Paisagem, conforme descrito acima, trata-se de um projeto de dança que não se dá nos espaços tradicionais reservados à dança, como as salas de ensaio e os teatros italianos (com sua configuração espacial de palco e plateia); trata-se de um projeto que tem todo o seu processo de investigação e todas as suas ações e apresentações realizadas em espaços públicos não destinados à dança, como por exemplo, as ruas e praças do centro da cidade de São Paulo e diversos espaços pertencentes ao CCSP (Centro Cultural São Paulo) como, por exemplo, jardim suspenso, rampas, escadas, espaços expositivos, subsolo, porão, cafeteria, etc. É um projeto que visa criar a partir dos contextos e situações, podendo ser considerado como um projeto ligado à Arte Contextual, conforme proposta por Paul Ardenne (2004, p. 10):

Estábamos invitados a contemplar el arte en unos lugares identificados, emblemas del poder económico o simbólico, tales como la galería de arte o el museo. Muchos artistas van a abandonar estos perímetros sagrados de la mediación artística para presentar sus obras, unos en la calle, en los espacios públicos o en el campo [...]. Para éstos, herederos del realismo histórico [...], el arte tiene que ir ligado a las cosas de todos los días, producirse en el momento, en relación estrecha con el "contexto", precisamente.

Bajo el término de arte "contextual" entenderemos el conjunto de las formas de expresión artística que difieren de la obra de arte en el sentido tradicional: arte de intervención y arte comprometido de carácter 
activista (happenings en espacio público, "maniobras"), arte que se apodera del espacio urbano o del paisaje (performances de calle, arte paisajístico en situación...), estéticas llamadas participativas o activas en el campo de la economía, de los medios de comunicación o del espectáculo.

Assim como as artes visuais, a dança também realizou, ao longo de sua história, um movimento de saída de seus espaços tradicionais, como salas de ensaio e teatros, deslocando criações para espaços públicos, inserindo-se em paisagens urbanas e espaços não-convencionais, e incluindo movimentos cotidianos (movimento pedestre), existentes comumente nas ruas, como repertório de dança. ${ }^{3}$ Colocou-se em cheque a noção de espetáculo, sendo possível vislumbrar novos parâmetros para a dança que recusam o virtuosismo e o ilusionismo, e que buscam uma relação mais próxima com o espectador. Nesta perspectiva, o suposto espaço ideal e neutro para a realização da dança, representado pelas salas de ensaio e os teatros italianos, é questionado e problematizado. Esses espaços neutros, comumente encarados como páginas em branco, onde o bailarino tem liberdade para expressar sua movimentação sem tropeços em chãos desnivelados ou em objetos que podem obstruir a passagem, costumam provocar certa cegueira em relação ao reconhecimento de que são espaços específicos que suscitam certas relações específicas com nossos corpos. Longe de ser um espaço neutro, trata-se apenas de uma possibilidade de relação entre corpo e espaço e não a relação ideal entre corpo e espaço. A arte contextual vem, portanto, colocar uma lente de aumento na importância de se ter em conta o contexto de cada criação, sua especificidade e parcialidade. Estes espaços ideais e neutros, na verdade, carregam em si toda uma história e uma construção cultural e social que não devem ser apagadas ou desconsideradas.

Sobre esses espaços ideais, André Lepecki (2010) escreve que, na história da dança e da coreografia, a primeira condição para a dança ocorrer é a

\footnotetext{
${ }^{3}$ Nesse sentido, um importante momento histórico de rompimento e de busca de novos parâmetros para a dança se deu com o surgimento da dança pós-moderna americana na década de 1960, sobretudo as contribuições de Steve Paxton, Yvone Rainer e Trisha Brown dentro do movimento Judson Dance Theather, em Nova York. Esse movimento foi uma importante referência para o desenvolvimento do projeto Corpo e Paisagem. Para saber mais sobre esse movimento e sobre a saída da dança dos espaços tradicionais para ocupar espaços não-convencionais e urbanos, consultar: Ropa, 2012.
} 
terraplanagem, ou seja, o chão tem que ser em primeiro lugar um chão liso a fim de que o bailarino possa deslizar sem interrupções. No entanto, segundo Lepecki, esse espaço supostamente neutro esconde na verdade a violência que foi necessária para tornar seu chão liso e plano. O ato de neutralizar o espaço é um ato violento.

Para que a dança possa se dar, e, ao se dar, dar-se soberanamente, sem tropeços, interrupções ou escorregões, seu chão tem de ser antes de mais nada um chão liso, terraplanado, calcado e recalcado. O som que anima e precede a dança não é o som da natureza nem dos pássaros, de liras, batuques ou cantos: é a barulheira da maquinaria pesada, o palavrar ou as canções de trabalho dos operários, o chincalhar das ferramentas, o vociferar dos topógrafos e capatazes. Apenas depois de um chão se tornar tão liso, vazio e chato como uma folha de papel em branco [...], o dançarino pode entrar em cena, de modo que sua execução de passos e saltos não tenha de negociar "acidentes de terreno". Ora, esses acidentes não são mais do que as inevitáveis marcas das convulsões da história na superfície da terra - cicatrizes de historicidade. É como se uma topografia da dança já indiciasse a predileção dessa arte pelo esquecimento, o problemático a-historicismo constitutivo da dança. Se Deleuze nos falou da folha em branco como repleta de clichês que devem ser desfigurados de modo que algo novo possa se expressar em seu plano, o caso aqui é de um espaço branco repleto da violência que o fez e que o constituiu como ilusoriamente "neutro". (Lepecki, 2010, p. 14).

Lepecki nos faz lembrar que este espaço considerado ideal para a dança está na verdade carregado de história e de uma relação violenta, e que seu chão tornado liso e plano esconde muitas relações de opressão que tentam ser esquecidas a todo custo. Ao desenvolver a ideia de uma política do chão, Lepecki ressalta que esse chão tornado liso e aplainado vem refletir um gesto colonialista e de dominação que funda as cidades modernas; um gesto que visa neutralizar e apagar os acidentes do terreno e sua história, com "a criação de uma subjetividade sem um apego à terra” (Lepecki, 2017, p.181). Há a construção da ilusão de um sujeito automovente e autônomo, que pode ir e vir para onde quiser, graças a esses "terrenos previamente (re)calcados para o exercício pleno de seu delírio cinético" (Lepecki, 2010, p. 17). Essa valorização de uma mobilidade desenfreada se funda na suposição de que há a possibilidade do livre movimento, que, além de ser uma ilusão para aqueles que a exercem, também esconde o fato de que essa suposta 
mobilidade não é exercida por todos, mas sim por aqueles que detém esse privilégio. Pensar em uma política do chão (Lepecki, 2017) parte da percepção do âmbito político colonialista e hegemônico que subjaz nesse ato violento de tornar um chão liso e plano, provocando assim a dança a repensar seu fazer artístico, revendo as relações entre movimento e espaço estabelecidas em suas criações.

Assim, quando a dança passa a ocupar outros espaços normalmente considerados não ideais para seu livre desenvolvimento, habitando ruas da cidade, paisagens naturais e espaços não-convencionais, ao invés de se buscar um espaço livre de tropeços ou obstáculos imprevistos, busca-se colocar o corpo em contato com espaços do cotidiano que vêm carregados de uma história específica e que nada têm de neutros. Ao percorrer ruas, construções, praças, becos, ladeiras, vislumbra-se uma nova relação da dança com seus espaços, não apenas exigindo que os bailarinos enfrentem chãos sujos, esburacados, ásperos ou cheios de obstáculos, mas também que se relacionem com lugares que tem assumidamente uma história, que possuem uma dinâmica cotidiana específica e que já possuem habitantes ou transeuntes. Não é à toa que boa parte dos repertórios de dança realizados em salas de ensaio não possam ser simplesmente transportados para estes novos espaços. Exige-se outro corpo, outra qualidade de presença, outro estado de permeabilidade ao imprevisível, outra vestimenta, ou seja, a dança precisa ser revista. A dança que estou chamando aqui de contextual vai ao encontro de criações que se revelam no encontro com cada contexto em que o bailarino está inserido. A criação surge da relação entre o corpo e estas paisagens que o cerca, sendo assim um corpo situado e posicionado, que reconhece sua situação e que a assume.

Por sua vez, o espaço estéril e idealista puro dos modernismos dominantes foi radicalmente deslocado pela materialidade da paisagem natural ou do espaço impuro e ordinário do cotidiano. O espaço de arte não era mais percebido como lacuna, tabula rasa, mas como espaço real. o objeto de arte ou evento nesse contexto era para ser experimentado singularmente no aqui-e-agora pela presença corporal de cada espectador, em imediatidade sensorial da extensão espacial e duração temporal [...], mais do que instantaneamente "percebido" em epifania visual por um olho sem corpo. O trabalho site-specific em sua primeira formação, então, focava no estabelecimento de uma relação inextricável, 
indivisível entre o trabalho e sua localização, e demandava a presença física do espectador para completar o trabalho. (Kwon, 2008, p. 167).

Apesar do notório movimento da dança em ocupar diferentes tipos de paisagens, é interessante notar como os teatros italianos ainda são identificados como espaços privilegiados para se assistir dança. Além do chão terraplanado e liso presente nos palcos, trata-se de um espaço que se propõe neutro e apartado dos espaços cotidianos da cidade, onde é possível uma experiência estética ilusionista e sublime. Um espaço com uma distribuição palco-plateia que preza pela frontalidade e pela imobilidade do espectador, com um único ponto de vista de onde se assiste esta dança. Esse único ponto de vista do espectador revela a ideia de que há um ponto de vista ideal de onde se pode ter uma visão distanciada e correta do espetáculo. Os espectadores são convocados a permanecerem parados, contemplando à distância, a partir de determinada perspectiva.

Essa relação espacial nos remete à criação da noção de perspectiva nas artes visuais, que surgiu, dentro da história da pintura, como uma tentativa de conseguir representar bidimensionalmente a tridimensionalidade: um efeito perspectivo criado a partir de um único ponto de fuga em uma superfície plana. "O efeito perspectivo depende de um ponto de vista central" que tem o objetivo de "harmonizar o olhar do espectador" (Lepecki, 2017). Essa representação perspectiva se constituiu quando a pintura passou a ter uma pretensão de verdade, que só seria alcançada a partir da organização da pintura em um único ponto de fuga, um único ponto de vista.

Panofsky nos faz lembrar ainda que "a perspectiva central cria duas suposições tácitas, mas essenciais: primeiro, que nós enxergamos com um olho imóvel e unitário; e segundo, que a secção transversal plana da pirâmide visual pode passar como uma reprodução adequada de nossa imagem ótica" (Panofsky, 1997:29). Portanto a perspectiva sempre opera por redução. E o que é reduzido na perspectiva não é apenas a tridimensionalidade do espaço, mas a natureza corporalizada da percepção, já que o embasamento corpóreo da sensação cede seu lugar para algoritmos de visibilidade. O que se perde assim é a corporificação da visão, por meio de uma operação que subtrai à percepção os nossos olhos continuamente moventes, descentralizados, estereoscópicos, substituindo-os por um ponto de vista monomaniacamente fixo e 
artificialmente monocular. (Lepecki, 2017, p. 141).

A ideia de um único ponto de vista ideal de onde o espectador deve contemplar a obra está presente no teatro italiano e em sua distribuição espacial palco-plateia, trazendo em si a concepção de uma percepção ideal que é única e imóvel, e, portanto, descorporificada. É uma ideia de percepção em oposição à ação, como se para perceber algo fosse preciso estar parado. No entanto, em realidade, a percepção corporal se dá pelo movimento, com ação e percepção como um ato único. A ideia de um ponto de vista fixo de onde é possível apreender a totalidade ou a verdade de algo é ilusória e só é possível se imaginamos uma percepção sem corpo. O ponto de vista do espectador em um palco italiano está longe de ser neutro ou ideal, trata-se de uma configuração espacial que tem especificidades e que carrega uma história pautada em relações de poder e de sujeição. O questionamento destes espaços privilegiados da dança, como as salas de ensaio e os teatros italianos, nos impulsiona a sairmos da comodidade de certa cegueira sobre as relações de poder por eles instituídas, buscando retomar uma percepção corporificada, localizada e situada.

\section{Pontos de vista}

Na segunda versão do projeto Corpo e Paisagem, a intervenção À Beira de Si, criada coletivamente pelo Grupo de Investigação Subjetividade e Intimidade, configurou-se como uma longa trajetória que foi realizada pelo público juntamente com os performers por diversos espaços do CCSP (porão, subsolo, escadas, espaço expositivo, jardim dos fundos, rampas e jardins suspensos), com duração aproximada de 1h30m. Antes do início, eu dava algumas orientações ao público, esclarecendo que faríamos um percurso e que, neste caminho, realizaríamos algumas intervenções e composições com as diversas paisagens pelas quais passaríamos. Ressaltava que o importante para cada participante era a experiência da caminhada, procurando abrir o próprio olhar e os demais sentidos para perceber de maneira mais sensível as paisagens pelos quais passávamos, tendo 
liberdade de escolher os pontos de vista de onde se podia observar e se relacionar com o espaço, os objetos e as pessoas. Assim, o espectador era convidado a se dar conta de que seu simples ato de escolher certo ponto no espaço para posicionar o corpo e o olhar já se constituía como um ato compositivo que alterava a paisagem, tanto quanto as composições dos corpos dos performers.

Não havia um ponto de vista ideal de onde se deveria assistir a performance, ao contrário, buscava-se evidenciar que a localização de cada espectador era uma possibilidade dentre muitas outras de olhar e perceber. A escolha de cada espectador de como construir sua própria maneira de se relacionar com a performance evidenciava que cada uma dessas escolhas alterava e compunha com as situações e os espaços, não sendo portanto um olhar neutro, imóvel e distanciado, mas sim situado, móvel e corporificado. A forma como cada espectador se colocava perante os espaços e perante as performances, transformava cada espaço e se constituía como uma participação, mesmo que sua intenção fosse apenas contemplar ou perceber.

Durante a intervenção, o fato da trajetória ser realizada com os performers e os espectadores juntos, sem que esses estivessem identificados, somado à liberdade dada ao público com relação aos seus pontos de vista gerou uma maior diluição das fronteiras entre artistas e espectadores, sendo possível observarmos não apenas as composições realizadas pelos performers como também aquelas criadas pelos próprios espectadores. Complexificando ainda mais estas questões, havia também uma outra camada de público, que não estava realizando a trajetória conosco, e que era formada por frequentadores e transeuntes do CCSP, que passavam pelos espaços no momento das intervenções. Esta camada de espectadores às vezes também se tornava foco de observação da outra camada de espectadores, tornando-se também parte da intervenção, ao mesmo tempo em que também observava as composições geradas pelo nosso grupo de caminhantes. Além disso, os próprios performers se colocavam em um estado de percepção e contemplação das paisagens e das situações pelas quais eles passavam, criando performances que eram permeáveis a cada contexto, aos movimentos dos espectadores, não se colocando portanto em uma posição 
apartada ou descontextualizada. Afinal, quem observava quem? Quem estava compondo e modificando as paisagens? Quem era paisagem para quem? Onde se encontrava o fenômeno da observação, da percepção e da contemplação?

Parte desta discussão foi trabalhada de diversas outras maneiras durante as práticas dos Grupos de Investigação das duas versões do Projeto Corpo e Paisagem, ainda em caráter de experimentação. Uma destas experiências é particularmente interessante para nossa discussão, por isso descrevo-a a seguir.

Trata-se de um dispositivo de jogo com algumas regras que se iniciava com todos os participantes sentados em cadeiras formando um círculo. ${ }^{4}$ A proposta geral do jogo era a de que cada participante tinha liberdade para trocar sua cadeira de posição, quantas vezes quisesse, a fim de assumir certos pontos de vista de onde the parecesse mais interessante observar longamente as paisagens descortinadas à sua frente. A única restrição e principal regra do jogo era a de que, ao posicionar sua cadeira, cada participante não podia perder do seu campo de visão a pessoa que estava sentada à sua direita no círculo inicial. Ou seja, esta pessoa sempre deveria estar no seu campo de visão e sempre faria parte da paisagem que este estava a contemplar. Assim, quando o jogo começava, aos poucos a formação circular inicial ia se desfazendo à medida que cada participante assumia a liberdade de levantar-se carregando sua cadeira para posicioná-la em algum outro ponto do espaço, criando múltiplas possibilidades de composições no espaço. Uma interessante característica deste jogo estava em perceber que, enquanto um participante está contemplando certa paisagem, ele também compõe e faz parte da paisagem de outra pessoa que está contemplando. ${ }^{5}$ Assim, cada participante podia dar-se conta que era, ao mesmo tempo, espectador e performer, experimentando uma dança entre esses papéis e uma quebra das supostas polaridades passivo-ativo, percepção-ação, corpo-paisagem. Quem é

\footnotetext{
${ }^{4}$ Este dispositivo de jogo foi livremente inspirado em proposições do artista-interventor espanhol Diego Agulló.

${ }^{5}$ Esta prática com as cadeiras descrita acima foi realizada em duas ocasiões dentro do Projeto Corpo e Paisagem. A primeira ocorreu durante a primeira versão do projeto, nos arredores do CRD (Centro de Referência da Dança), ou seja, o jogo percorreu o Vale do Anhangabaú, o Viaduto do Chá e ruas próximas ao Teatro Municipal de São Paulo, e durou aproximadamente 1h30min. A segunda vez ocorreu na segunda versão do projeto, durante o Grupo de Investigação Sensorialidade, percorrendo diversos espaços do CCSP (Centro Cultural São Paulo), com duração aproximada de 1 hora.
} 
espectador de quem? Quem contempla e quem compõe? O ponto de vista de quem contempla já não se constitui como uma composição? Há uma separação entre o corpo de quem contempla e a paisagem em que está inserido?

\section{Visão Encarnada}

Como ver? De onde ver? Quais os limites da visão? Ver para quê? Ver com quem? Quem deve ter mais de um ponto de vista? Nos olhos de quem se joga areia? Quem usa viseiras? Quem interpreta o campo visual? Qual outro poder sensorial desejamos cultivar, além da visão? (Haraway, 1995, p. 28).

As ações do projeto Corpo e Paisagem, descritas acima, trabalham com a ideia de uma criação em dança contextualizada, em que o corpo é chamado a relacionar-se com cada paisagem, com sua textura, cheiro, arquitetura, chão, temperatura, forma e cor; características da paisagem que indicam certa história e que sugerem formas de habitá-la. A criação se dá a partir de certa localização e situação e está a todo momento dialogando e tomando consciência deste ponto de vista de onde ela ocorre. Por isso, as intervenções finais resultantes de cada grupo de investigação foram compartilhadas com o público trazendo em seus formatos e proposições a necessidade de evidenciar esta localização e situação ao espectador, despertando uma maior consciência destes espaços habitados, de suas histórias e peculiaridades, bem como despertando a consciência de que o ato do espectador, ou seja, o ato de observar, perceber e contemplar a performance, também é um ato situado neste espaço e também se relaciona com cada contexto, assumindo-o e transformando-o, à medida em que cada espectador percebe seu próprio corpo se posicionando, experimentando e escolhendo certos pontos de vista. Portanto, no projeto Corpo e Paisagem, recusase a ideia de que há um ponto de vista único ideal de onde se deve observar, um ponto de vista que olha de fora a partir de um lugar neutro, um ponto de vista sem um corpo de onde é possível apreender a verdade das coisas. Busca-se reencontrar a experiência de uma visão encarnada, parcial e situada.

Donna Haraway (1995) escreve sobre a importância do conhecimento se dar 
a partir da visão que nasce de um corpo, com suas complexidades e posicionamentos, indo ao encontro de uma visão parcial e não universal, sendo, portanto, contrária à ideia de universalidade proposta em um pensamento hegemônico da ciência. O ideal da ciência patriarcal visa poder observar de forma objetiva e distanciada para seus objetos de conhecimento, analisando-os de um ponto de vista privilegiado para chegar a uma verdade sobre esses objetos. Nesta perspectiva, Donna Haraway faz um estudo sobre a experiência da visão, percebendo inicialmente como este sentido corporal foi sendo apropriado pela ciência de forma a tratá-lo como um ato distanciado e descorporificado, para posteriormente defender a volta a uma experiência visual corporificada e situada.

Gostaria de continuar apoiando-me metaforicamente num sistema sensorial muito difamado do discurso feminista: a visão. A visão pode ser útil para evitar oposições binárias. Gostaria de insistir na natureza corpórea de toda visão e assim resgatar o sistema sensorial que tem sido utilizado para significar um salto para fora do corpo marcado, para um olhar conquistador que não vem de lugar nenhum. Este é o olhar que inscreve miticamente todos os corpos marcados, que possibilita à categoria não marcada alegar ter o poder de ver sem ser vista, de representar, escapando à representação. (Haraway, 1995, p. 18).

Segundo Donna Haraway (1995), o olhar tem sido usado na história da ciência de uma maneira perversa, vinculado ao militarismo, ao capitalismo, ao colonialismo e à supremacia masculina, em busca de um poder absoluto. Faz-se necessário, portanto, que possamos nomear onde estamos e onde não estamos, percebendo a corporificação específica e particular da visão, não caindo na ilusão de uma visão que transcende os limites e as responsabilidades. "Apenas a perspectiva parcial promete visão objetiva" (Haraway, 1995). Esta objetividade que vem de uma localização limitada e de um conhecimento localizado é chamada aqui de objetividade feminista. "A partir desse pensamento, podemos nos tornar responsáveis pelo que aprendemos a ver" (Haraway, 1995). Nossos olhos são sistemas de percepção ativos, que constroem traduções e modos específicos de ver, sendo importante percebermos como estes sistemas visuais funcionam tecnicamente, socialmente e psiquicamente. 
Muitas correntes do feminismo tentam estabelecer bases teóricas para uma confiança especial na perspectiva dos subjugados; há boa razão para se acreditar que a visão é melhor abaixo das brilhantes plataformas espaciais dos poderosos [...]. Vinculado a essa suspeita, este texto é um argumento a favor do conhecimento situado e corporificado e contra várias formas de postulados de conhecimento não localizáveis e, portanto, irresponsáveis. Irresponsável significa incapaz de ser chamado a prestar contas. Há grande valor em definir a possibilidade de ver a partir da periferia e dos abismos. (Haraway, 1995, p. 22).

Esta defesa de um olhar limitado e situado, que assume e tem consciência de seu ponto de vista, recusa a busca por uma posição inteira e total que procura o objeto perfeito e fetichizado, fazendo com que a ótica seja uma política de posicionamentos. "Posicionar-se é, portanto, a prática chave" (Haraway, 1995), implicando em responsabilidade e vulnerabilidade, buscando redes de posicionamentos diferenciais, e resistindo a uma política de finalidade e de simplificação. ${ }^{6}$ Portanto, estas várias visões encarnadas e situadas não tentam transcender seus limites, como se tratasse de uma única visão de cima, mas procuram se nomear como visões parciais e vozes vacilantes que vivem dentro de limites e que veem desde algum lugar.

Estou argumentando a favor de políticas e epistemologias de alocação, posicionamento e situação nas quais parcialidade e não universalidade é a condição de ser ouvido nas propostas a fazer de conhecimento racional. São propostas a respeito da vida das pessoas; a visão desde um corpo, sempre um corpo complexo, contraditório, estruturante e estruturado, versus a visão de cima, de lugar nenhum, do simplismo. Só o truque de deus é proibido. (Haraway, 1995, p. 30).

Ao transpormos estas reivindicações de Donna Haraway a favor de uma visão encarnada e situada para o campo das artes e, mais especificamente, da dança, voltamos às considerações de André Lepecki sobre o quanto a dança traz certa predileção pela descontextualização de suas práticas, ao estabelecer relações com o espaço que privilegia o espaço neutro como uma página em branco e a

\footnotetext{
${ }^{6}$ Essa questão nos faz refletir sobre como, em nosso dia a dia, os posicionamentos e a possibilidade de ver a partir de certos pontos de vista são regidos por determinantes sociais e políticos que têm o poder de excluir, controlar ou limitar esses posicionamentos de acordo com as características de gênero, étnicoraciais, classes sociais, etc., que, de alguma forma, se explicitam no corpo. A quem é dado o privilégio de ver a partir de certos pontos de vista? Quem está apartado ou excluído? Como uma ação artística pode abalar e mover essas questões?
} 
visão ideal do espectador a partir de um único ponto de vista imóvel e descorporificado. Como a dança, ao se rever e traçar um olhar crítico sobre essas práticas, pode trazer contribuições na investigação da sensorialidade do corpo e da visão encarnada, ativando maneiras situadas de criar e perceber seus entornos?

\section{Sensorialidade}

Como o próprio nome já diz, um dos pontos de partida do projeto Corpo e Paisagem está na discussão da relação entre o corpo e a paisagem, propondo diversas práticas que problematizam as visões hegemônicas de nossa sociedade acerca dessa relação. A noção de visão distanciada, descorporificada e com um único ponto de vista ideal, conforme discutimos acima, também está presente dentro do domínio da geografia, já que algumas de suas vertentes encaram a paisagem como algo a ser visto de fora, a partir de um mirante, com uma visão aérea de onde, supostamente, é possível ter a totalidade da visão, sendo portanto herdeiras de uma ciência que tem a pretensão de descobrir verdades. Trata-se de uma visão sem um corpo. No entanto, as abordagens fenomenológica (Dardel, 2015; e Besse, 2014) e humanista (Tuan, 2012; e Santos, 2017) da geografia recusam esta vista ideal de cima e defendem que a paisagem é habitada por dentro, com suas texturas e nuances, a partir de todos os sentidos do corpo e não unicamente da visão. Nessa perspectiva, o ser humano e a paisagem nunca podem ser totalmente separados, estando profundamente imbricados um no outro. Assim, a paisagem é vivida a partir de um corpo situado e em contato com seu entorno, onde há uma visão encarnada e onde o corpo percebe e se move a partir de todos os seus sentidos.

A resposta por meio da vista, para o mundo, é diferente, em vários aspectos importantes, da resposta por meio dos outros sentidos. Por exemplo, ver é "objetivo" [...]. Ver não envolve profundamente as nossas emoções. [...]. Uma pessoa que simplesmente "vê" é um expectador, um observador, alguém que não está envolvido com a cena. O mundo percebido pelos olhos é mais abstrato que o conhecido por nós por meio dos outros sentidos. Os olhos exploram o campo visual e dele abstraem alguns objetos, pontos de interesse, perspectivas. Mas o gosto do limão, 
a textura de uma pele quente, e o som do farfalhar das folhas nos atingem como sensações. [...]. Os objetos distantes somente podem ser vistos como "distantes" - como não provocando nenhuma resposta emocional forte -, embora possam estar bem próximos de nós. (Tuan, 2012, p. 28).

Acima, Tuan aborda a experiência da visão como distante, sem envolvimento, como um sentido de onde é possível vermos de fora, de um ponto de vista distanciado. No entanto, quando Tuan aborda a experiência dos demais sentidos corporais, ressalta o quão difícil se torna manter este lugar de distanciamento, por exemplo, ao sentirmos um cheiro ou um toque. Ora, se aqui neste texto estamos à procura de uma visão encarnada e não distanciada, estamos tratando de uma visão que tem um corpo e que, inevitavelmente, está a todo momento permeada das experiências com os demais sentidos. De que forma a experiência com os demais sentidos pode trazer um novo frescor para a visão, devolvendo-lhe seu lugar de visão encarnada?

Na primeira versão do projeto Corpo e Paisagem, realizado no CRD, realizei diversas práticas com os participantes do projeto em que havia restrição da visão. Uma dessas práticas foi inspirada livremente em um exercício proposto por Lisa Nelson ${ }^{7}$ em um curso do qual tive o privilégio de participar em 2006. Durante a realização de Corpo e Paisagem, no CRD, este exercício de Lisa ganhou novos contornos devido à temática abordada no projeto. Resumidamente, a proposta foi a de nos dividirmos em duplas, onde um estaria vendado (ou seja, sem enxergar) e outro seria seu cuidador, para então sairmos em uma espécie de deriva às cegas nos entornos do CRD, pelas ruas do centro de São Paulo, tendo como ponto de partida a frente do Teatro Municipal. Cada pessoa vendada saia em caminhada pelas ruas da cidade, procurando experimentar cada paisagem a partir dos demais sentidos do corpo, seja pelo toque, pelo cheiro, pelo paladar ou pelo som. As pessoas privadas da visão não eram conduzidas pelo seu cuidador, elas que decidiam para onde ir, o que fazer, desenvolvendo sua própria trajetória, sendo o cuidador aquele que cuidava para que a pessoa vendada não se machucasse ou

Lisa Nelson é uma artista da dança norte-americana, uma das principais referências no estudo da improvisação. Tive a oportunidade de participar de um workshop ministrado por ela no Estúdio Nova Dança, em São Paulo, em janeiro de 2006. 
se colocasse em perigo, interferindo através do toque apenas nestes momentos perigosos. Tratou-se de uma experiência muito rica e intensa, que suscitou um sentimento de pertencimento às paisagens de São Paulo, revelando camadas surpreendentes das reentrâncias da cidade.

El paisaje es, ante todo, algo vivido. La experiencia del paisaje es, por tanto, una experiencia del cuerpo, entre lo somático y lo sensible. El paisaje es, por tanto, algo que solicita todos nuestros sentidos y no únicamente la vista: es algo que olemos y respiramos, que tocamos y nos toca, sobre lo que caminamos, el aire que golpea nuestro rostro, el sonido y la luz. El paisaje nos atraviesa y nos impregna: es aquello en lo que nos adentramos y donde dejamos huellas y rastros, y que deja huellas y rastros en nosotros. De ahí, por ejemplo, la reciente centralidad del caminar, de la marcha como práctica paisajera en los trabajos de Richard Long o Hamish Fulton y, sobre todo, en la reflexión ensayística de Rebeca Solnit y Francesco Careri, por citar a los más conocidos. (VAlverde, 2017, p. 150).

Na segunda versão do projeto Corpo e Paisagem, realizado no CCSP (Centro Cultural São Paulo), durante as pesquisas do Grupo de Investigação Sensorialidade, realizamos práticas que visavam experimentar as paisagens do CCSP privilegiando algum dos sentidos do corpo, tendo sido realizadas muitas experiências sem a visão e com o uso de vendas. Essas práticas levaram à criação da intervenção Escuro, aberta ao público em geral, que se configurou como uma proposta de experiência sensorial em que os espectadores eram convidados a participar vendados, ou seja, sem o sentido da visão, de uma trajetória que percorria a biblioteca e parte do subsolo do CCSP. Diferentemente da prática de deriva às cegas realizada na primeira versão do projeto no CRD, agora cada espectador vendado era conduzido por um de nós, participantes do grupo de investigação, por uma trajetória pré-definida, em uma relação de estreita confiança onde era possível experimentar, ao longo do trajeto, o aguçamento dos outros sentidos do corpo, principalmente a audição, o olfato e o tato.

Durante esta trajetória, foram escolhidos alguns poucos pontos de pausa, dentro da biblioteca do CCSP, em que o espectador sentava-se em uma cadeira estrategicamente posicionada e retirava a venda por alguns instantes, podendo surpreender-se com o reconhecimento visual do local onde se encontrava e do 
ponto de vista que ocupava, experimentando o sentido da visão com um novo frescor, mais relaxado para sentir as nuances das imagens. O posicionamento destas cadeiras foi escolhido tendo como inspiração o jogo das cadeiras já descrito acima neste texto, ou seja, privilegiamos pontos de vista em que se descortinavam paisagens em que algum outro espectador estava inserido, sentado em sua cadeira e observando algum outro campo de visão. Assim, evidenciávamos os vários pontos de vista de onde observar, bem como o fato de que cada espectador era também cena ou paisagem para a contemplação de outrem, o que trazia maior consciência ao espectador de sua inserção na paisagem e da parcialidade e especificidade de seu ponto de vista. Nestas pausas sem venda, nós cuidadores realizávamos algumas composições e intervenções sutis naqueles espaços, criando uma camada de estranhamento frente a um funcionamento normal de uma biblioteca. No entanto, vale ressaltar que a grande maioria do tempo da intervenção (que durava aproximadamente 1h15min) se dava com os espectadores vendados, sendo apenas 4 momentos muito pontuais e curtos em termos de duração, em que houve pausas sem a venda, quase como flashes de máquina fotográfica.

Acostumados a viver em uma sociedade em que há a primazia do sentido da visão em detrimento da experiência com os outros sentidos, Escuro tinha como principal proposição provocar uma quebra do padrão perceptivo de cada pessoa, privando-a de seu sentido principal, para que pudesse sentir, tanto a paisagem quanto a obra artística, não como imagens para serem vistas e observadas de fora a partir de um ponto de vista distanciado, mas sim como criações em que se está totalmente inserido e do qual se faz parte.

El público deja de ser una entidad exterior a la obra, como había anticipado ya la performance, para pasar a formar parte de esa situación de desconocimiento, una experiencia compartida, un viaje a lo incierto. Esto no niega el lugar de los espectadores como una mirada que abre una distancia de crítica y reflexión, sino que los recoloca en un sistema de relaciones en el que artistas y no artistas, instituciones y personas, humanos y objetos, entran a formar parte de un plano de horizontalidad que se sostiene el tiempo que dura un proyecto, obra o ficción. Es durante estos tiempos que el arte, no solo como obra, sino antes que eso como forma práctica de ponerse en relación, genera pequeñas comunidades 
sensibles. (Cornago, 2019, p. 39).

Além das múltiplas sensações que cada espectador experimentava durante a trajetória às cegas, algo nas paisagens também se modificava. A presença de corpos mais vulneráveis sendo guiados e cuidados por uma outra pessoa gerava um impacto bastante grande nos espaços percorridos da biblioteca. Para os frequentadores ordinários da biblioteca, quem estava performando? Para os espectadores-participantes da intervenção, quem eram os performers? E nós, enquanto condutores do público, que função adquiríamos ali? Quem assistia quem? A ideia de contemplação sem o sentido da visão ganhava quais novas tonalidades? O que era um estado contemplativo? De que forma um corpo mais vulnerável e menos adaptado à paisagem pode ganhar potência e propiciar experiências mais significativas?

Esta experiência sensorial levou à experiência de um corpo vulnerável e, exatamente por isso, mais sensível aos atravessamentos que o mundo nos traz, um corpo menos produtivo e eficaz, mais lento e tateante, com trajetórias mais sinuosas e titubeantes, mais suscetível a pequenos sons e cheiros, ao toque das mãos em uma parede, à sensação de frio ou calor, o vento, o som das conversas ao lado, com suas vozes aveludadas ou estridentes. A caminhada, habitualmente encarada como um ato banal, automático e com trajetórias objetivas, ganha sensibilidade na sola dos pés, revelando ao caminhante vendado as inúmeras irregularidades do chão, sua aspereza, seus desnivelamentos, retirando do corpo caminhante a ilusão automovente e fazendo-nos relembrar que este chão, aplainado por uma lógica colonialista, exala os fantasmas recalcados que o habitam. A caminhada às cegas, com sua velocidade lenta, seus desequilíbrios e tropeços, arranca o cidadão da lógica produtivista e acelerada das cidades modernas, quebrando com os requisitos cinéticos vinculados às ideologias de pertencimento e exclusão, desafiando "o pressuposto do livre movimento como algo dado a todos os cidadãos, ao trazer à tona como certos sujeitos mantém uma relação muito diferente com a motilidade, a verticalidade, a circulação e o próprio chão." (Lepecki, 2017, p. 178). 
Esse corpo movente titubeante deixava de ser sentido apenas frontalmente, comandado pela visão, e ganhava percepção nas costas e dos lados, em uma percepção mais tridimensional do corpo e das paisagens. Assim, tanto as paisagens quanto a obra artística deixavam de ser identificadas como fotos bidimensionais a serem vistas, para se tornarem ambientes tridimensionais, onde se pode adentrar e sentir texturas e dobras, ganhando dimensões e nuances em uma percepção do corpo que percebe com a sola dos pés, com as costas e com o topo da cabeça. O corpo assim ganha volume, e respira, preenche e habita a paisagem, reconhecendo sua implicação no mundo através do envolvimento pelos sentidos e da profunda sensação de pertencimento às paisagens.

\title{
Perceber-Agir / Contemplar-Criar
}

\begin{abstract}
Os gestos e os deslocamentos se dão como percepções mais refinadas das intensidades do espaço, da arquitetura, seja da cenografia, seja do lugar em si mesmo. É possível, então, falar de um movimento dançado como leitura do espaço e do tempo, mais amplamente do contexto, uma leitura sensível, em curso, do espaço. Não há diferença de natureza entre perceber e fazer, ou, antes, o perceber já é sempre uma ação. É assim que outro binarismo, o que opõe passivo e ativo, é retomado. A percepção, habitualmente passiva, não se opõe mais, aqui, à ação. Na atenção multissensorial do corpo dançante, toda percepção é ativa e a atividade é a da percepção. Esse binarismo entre passividade e atividade é constitutivo de dualismos tão diversos quanto fortes na construção do pensamento ocidental, como entre contemplar e agir, entre corpo e espírito, ou, indiretamente, entre feminino e masculino. O abalo da impermeabilidade entre as duas funções da oposição binária constitui, assim, um deslocamento forte, aqui apenas indicado, nos termos da filosofia da percepção, da estética, mas também da política. (Bardet, 2014, p. 228).
\end{abstract}

Conforme vimos nas duas intervenções descritas acima, À Beira de Si e Escuro, o espectador era convidado a caminhar e a se posicionar, experimentando as performances e as paisagens a partir da imersão de seu corpo em movimento, seja através da escolha e vivência de diferentes pontos de vista no espaço, seja através da vivência de seus gestos e deslocamentos, com ou sem venda, percorrendo os espaços. A experiência sensorial da paisagem e da obra artística por parte dos participantes-espectadores não foi puramente visual, estática e 
distanciada, mas sim uma experiência que percorreu e adentrou suas nuances, percebendo-as em movimento e através do movimento do corpo. Introduziu-se uma maneira de perceber a paisagem diferente daquela de quem observa a partir de um mirante, pois além de estar próximo e dentro da paisagem, o observador não permanece estático, mas sim em movimento, fazendo com que o ato de andar introduza um ritmo e uma temporalidade à percepção (Veloso, 2017). O mesmo ocorreu com relação à percepção da obra artística: ao invés de observar de fora a partir de um ponto de vista supostamente imóvel, ideal e distanciado, o espectador se vê inserido na performance, percorrendo-a de dentro e, inevitavelmente, compondo com ela a partir de seus gestos e suas escolhas de pontos de vista. Percepção e movimento se revelam aqui como um ato único: eu caminho enquanto contemplo, eu construo enquanto percebo, eu traço um desenho no espaço enquanto adentro em suas texturas e nuances. Esta diluição das fronteiras entre passivo e ativo possibilita devolvermos à percepção seu caráter criativo e à ação seu caráter sensorial, ou seja, perceber e agir estão intimamente ligados e não se realizam enquanto polaridades isoladas. "A percepção é uma atividade, um estender-se para o mundo." (Tuan, 2012, p. 30).

Perceber, ouvir o contexto, é uma atividade. É preciso que a percepção seja produção ou apresentação de alguma coisa, para que esse momento de improvisação não seja uma simples introspecção individual e dê alguma coisa em partilha. É preciso igualmente, para evitar ser uma simples transcrição da realidade, que esse lugar entre da percepção seja a oportunidade de uma intensificação, de um agenciamento, em poucas palavras: de uma composição. Em que medida a composição já está em jogo nesses movimentos de percepção? (Bardet, 2014, p. 196).

Essa inseparabilidade entre ação e percepção se faz presente tanto na experiência do espectador, como também na experiência dos criadores e performers, seja durante as práticas desenvolvidas na pesquisa dos grupos de investigação do projeto Corpo e Paisagem, seja nas performances finais realizadas junto aos espectadores. Tratava-se de estreitar as relações de cada pessoa (seja ela o artista ou o espectador) com seu próprio corpo e com o contexto em que se insere, a partir de um trabalho voltado principalmente a uma quebra dos padrões 
perceptivos e, consequentemente, uma quebra dos padrões motores.

Não posso mudar de gesto se não mudar a minha percepção. É uma ilusão acreditar que se podem aprender gestos por uma decomposição mecânica: tudo aquilo que chamamos de coordenações, os habitus corporais de alguém são, na realidade, habitus perceptivos. Portanto, tornara-se evidente para os dançarinos contemporâneos que se quisessem mudar a natureza de um gesto e sair de certa forma de repetição, não podiam fazê-lo senão passando por um trabalho com a percepção. (Godard, 2006, p. 74).

Mais do que querer provocar a participação ou a movimentação do espectador a fim de que ele se tornasse um co-criador ativo da obra artística, a real motivação do projeto Corpo e Paisagem estava em provocar novas maneiras de percepção aos espectadores, a fim de, quem sabe, se darem conta do caráter criativo e extraordinário do simples ato de perceber ou contemplar, ativando um estado de presença corporal, de atenção, de sensibilidade, de vulnerabilidade que amplia e aprofunda a sensação de habitar um corpo e de estar a todo momento se relacionando e se posicionando em seu contexto. A experiência do espaço vivido que se instaura no corpo através de sua sensibilização vislumbra-se como uma forma de resistência a um cotidiano contemporâneo que a cada dia se vê mais desencarnado e automatizado. Portanto, não se tratava de querer arrancar uma ação do espectador para tirá-lo de sua passividade, mas sim de ver nascer um novo estado de presença em seu corpo ao situá-lo em uma rede de eventos que solicita sua percepção e evidencia seus posicionamentos. Empresto a expressão "estabilidade dinâmica" do bailarino e improvisador Julyen Hamilton ${ }^{8}$ para desfazer mais um pouco essa dualidade passivo-ativo que permeia a suposta polaridade percepção-ação (Bardet, 2014). Hamilton fala da "estabilidade dinâmica" ao se referir ao estado corporal à qual o improvisador em dança deve se sintonizar, um estado que concilia as ideias de pausa e movimento, uma estabilidade que não está estagnada mas que se realiza através do mover-se. Ressalta, dessa forma, a

8 Julyen Hamilton, artista da dança de origem inglesa, é uma importante referência em dança no que se refere à linguagem da improvisação, com a qual tive a oportunidade de participar de um curso no espaço de dança La Caldera, em Barcelona, na Espanha. Para saber mais sobre o conceito de "estabilidade dinâmica" proposta por Julyen Hamilton, consultar: Bardet, 2014, p.206. 
importância do bailarino se manter flexível e móvel, tendo liberdade de escolher seus direcionamentos e gestos, mas sem perder de vista seu contexto e sua situação, e nem, tampouco, sua própria história e seus desejos e especificidades pessoais. Não é uma liberdade descontextualizada e inconsequente em que há o movimento pelo movimento, mas sim uma profunda consciência ao próprio corpo e às situações ali existentes naquele momento e naquele lugar. Esse é o estado corporal cultivado no projeto Corpo e Paisagem, seja nos performers ou nos espectadores, um estado permeado de responsabilidade e de vulnerabilidade.

Conforme Bardet (2014), esse embaralhamento entre passividade e atividade, com certa diluição dessa oposição, aponta para uma profunda revisão de uma série de dualismos presentes em nossa sociedade e que servem de base para discursos de exclusão e dominação. Assim, a revisão das polaridades percepçãoação e contemplação-criação ganha importância política, buscando uma quebra de padrões e abrindo novas possibilidades de relação com o corpo e com o mundo que não sejam tão regidas por discursos binaristas.

Ser espectador não é condição passiva que deveríamos converter em atividade. É nossa situação normal. Aprendemos e ensinamos, agimos e conhecemos também como espectadores que relacionam a todo instante o que veem ao que viram e disseram, fizeram e sonharam. Não há forma privilegiada como não há ponto de partida privilegiado. Há sempre pontos de partida, cruzamentos e nós que nos permitem aprender algo novo caso recusemos, em primeiro lugar, a distância radical; em segundo, a distribuição dos papéis; em terceiro, as fronteiras entre os territórios. Não temos de transformar os espectadores em atores e os ignorantes em intelectuais. Temos de reconhecer o saber em ação no ignorante e a atividade própria ao espectador. Todo espectador é já ator de sua história; todo ator, todo homem de ação, espectador da mesma história. (Rancière, 2012, p. 21).

\section{Artista-Espectador}

No Projeto Corpo e Paisagem, justamente porque a separação entre contemplação e criação se mostrou menos definitiva e marcada, o mesmo ocorreu com relação à separação entre artista e espectador. Movimentos e deslocamentos entre esses papéis marcam todo o projeto, desde seu processo criativo até suas intervenções finais. "Isso 
significa a palavra emancipação: o embaralhamento da fronteira entre os que agem e os que olham, entre indivíduos e membros de um corpo coletivo." (Rancière, 2012, p. 23).

Para a formação de cada grupo de investigação, realizaram-se inscrições abertas ao público em geral (maiores de 18 anos), sem exigência de qualquer formação artística ou em dança. O projeto abarcou pessoas de diferentes profissões, classes sociais, faixas etárias, orientações sexuais, identidades de gênero e étnico-raciais, havendo certa heterogeneidade em cada grupo. Os participantes tinham o desafio de pesquisar em conjunto por 1 mês e meio, para então criarem, de maneira coletiva e colaborativa, uma intervenção cênica a ser compartilhada com o público.

Com este modo de atuação, tecendo relações com o entorno, os grupos teatrais buscam trazer para a arena pessoas apartadas dos processos artísticos, convidando-os a participar da elaboração de discursos cênicos que efetivamente lhes digam respeito. O que faz que os artistas percam o controle total sobre a dinâmica criativa, disponibilizando-se para tomar rumos imprevistos, tanto na abordagem de temas quanto na investigação de linguagens e maneiras de articular o discurso que surgem da ação artística em curso. [...]. Contudo, em parte expressiva dos casos, as ações artísticas são deflagradas sem a necessária previsão do que acontecerá a seguir, estimulando os participantes a assumirem a gestão do processo, engajando-se como coautores, responsabilizando-se também pelas decisões que vão sendo tomadas pelo percurso investigativo. (Desgranges, 2012, p. 219, 220).

O projeto buscou, assim, viabilizar uma criação coletiva que surgisse dessa heterogeneidade de cada grupo. Nesse sentido, de que forma questões sociais inscritas no corpo através das características de gênero, étnico-raciais, de orientação sexual e de classe social puderam aparecer nas relações com os espaços, mesmo não tendo sido abordadas de maneira específica? Como as ideologias de pertencimento e exclusão influenciaram a forma com que cada participante se relacionou com os espaços pesquisados e com o grupo de criação? E como essas questões apareceram, ou não, nas intervenções realizadas? Para refletir sobre essas questões, trago um exemplo do grupo Subjetividade e Intimidade, desenvolvido no CCSP.

A pergunta disparadora para o início da nossa investigação coletiva foi: Qual o seu canto no CCSP? Um dos participantes do grupo escolheu uma parte bem escura do porão, onde ficavam depositados de maneira bastante caótica os restos 
de exposições e outros materiais não mais utilizados. A identificação do participante com aquele lugar precário, esquecido e invisibilizado parecia revelar uma vivência de exclusão e apagamento. Chamávamos esse lugar de porão dos restos. Um espaço amplo, muito sujo, escuro, fedorento, com ratos mortos, pedaços de painéis e obras, vidros quebrados, mobiliários inutilizados; um lugar muito inóspito e ao mesmo tempo instigante. Tratava-se de um lugar a ser esquecido no CCSP, onde é proibida a visita ou presença do público. Apesar disso, após negociações e conflitos, conseguimos autorização para circular por esse espaço durante a pesquisa e o incluímos na trajetória realizada pelo público durante as primeiras apresentações da intervenção $\dot{A}$ Beira de Si. Nas apresentações, os espectadores eram convidados a transitar livremente por esse espaço, em uma espécie de deriva, vivenciando uma temporalidade mais alongada em que nada acontecia além do simples ato de observar detalhes e contemplar aquela paisagem antes invisibilizada. Ao final dessa deriva, no meio desse porão escuro e fedorento, realizávamos uma festa de aniversário para o participante que escolhera aquele espaço, com direito a bolo, parabéns e discurso do aniversariante, causando assim uma sensação de estranhamento no público. O habitar esse espaço supostamente não-habitável e o criar a partir dele revelaram as entranhas do CCSP, aquilo que subjaz aos espaços luminosos, aquilo que está embaixo dos nossos pés ao deslizarmos tranquilamente pelo chão liso do espaço expositivo que fica logo acima. Revela, de certa maneira, esse habitar daqueles que são excluídos e que habitam lugares escuros e sujos, rentes ao chão, sendo um exemplo de como a performance deu voz aos apagamentos das histórias e das rachaduras que o gesto colonizador insiste em invisibilizar. ${ }^{9}$

O projeto, portanto, visava criar junto a esses habitantes da cidade,

\footnotetext{
9 Vale ressaltar que ao retomarmos essa mesma intervenção ao final de todo o projeto, realizando novas apresentações, a autorização anteriormente conseguida para ocupar o porão dos restos não foi renovada, ou seja, por conta de uma série de jogos de força presentes no CCSP, fomos proibidos de passar por esse espaço, fazendo com que tivéssemos que adaptar nossa performance. O lugar escolhido para substituir o porão dos restos foi um banheiro presente no subsolo. Ali, dentro de um banheiro escuro, realizamos nossa festa de aniversário. Essa proibição revelou ainda mais o quanto o ato de habitar o porão dos restos era subversivo e o quanto o gesto do participante ao escolher aquele espaço podia remexer em antigas estruturas de poder e de proibição presentes naquele centro cultural. Esse jogo de forças ali presentes em uma instituição reconhecida gera aqui muitos questionamentos impossíveis de serem totalmente abordados nesse texto, cabendo abordá-los com a devida atenção em um texto futuro.
} 
dialogando com as experiências de vida dessas pessoas, que, em sua maioria, nunca haviam participado de uma criação artística. Esses participantes dos grupos de investigação assumem tanto um lugar de público abarcado pelo projeto quanto de criadores, artistas e performers, "de maneira que a autoria do público não se faz presente somente na relação de leitura, mas já na relação de feitura" (Desgranges, 2012, p.219). Assim, a fim de realizar uma criação em dança contextual, ou seja, que considere a todo momento seu contexto e seus habitantes, o objetivo era que esta criação se desse a partir e conjuntamente com os habitantes dos espaços pesquisados, escutando e acolhendo como cada pessoa, com sua história e seu corpo, estabelecia sua própria maneira de habitar, perceber e criar aquelas paisagens cotidianas. Interessava dar voz e criar a partir desses "saberes localizados" e dessas "perspectivas parciais" (Haraway, 1995) que os participantes traziam, cada um à sua maneira, para o projeto, recusando assim a voz soberana e unívoca do artista que seria o detentor de alguma "verdade" ou de alguma "genialidade" a ser apresentada ao espectador.

Exploramos uma perspectiva que retira o espectador da posição de uma certa reverência à cena ou à voz unívoca de um falante, perspectiva ou posição essas que the ofereçam alguma mudança de lugar: com isso, desejamos mover a ideia que o público tem em relação ao que a cena sabe e apresenta a ele, e também ao que ele sabe e apresenta à cena. (Jardim, 2019, p. 292).

Os processos criativos que se estabeleceram foram bastante peculiares e proporcionaram não apenas a vivência da criação artística como também a possibilidade da formação de uma espécie de comunidade temporária, com relações de afeto, de parceria, de cooperação em busca de uma finalidade comum. A intervenção final criada por cada grupo carregava essa potência dos encontros e das relações, acolhendo e convidando uma nova camada de público (os espectadores que foram para assistir a performance) com a qual seria possível compartilhar a criação coletiva e colocá-la novamente em diálogo.

Gestos efectuados en común, obras concebidas con los espectadores o basadas en el hecho de compartir, creación, por los artistas, de estructuras de acogida, implicación colectiva en la lucha política o 
ecológica... Tantas prácticas contextuales cuya característica es implicarse en una acción común que considera al espectador como un ciudadano y como un ser "político". Característica que modifica de entrada la noción de público y revoca en particular el principio de pasividad, admitido como fundador de la relación con las obras de arte convencionales - una pasividad muy tradicional, donde sólo vibra la interioridad de quien mira la obra. El arte participativo, sin embargo, activa la relación directa, el intercambio físico, la reciprocidad inmediata, el todo vivido bajo los auspicios del contacto (podríamos hablar a este propósito de arte contactual). (Ardenne, 2004, p. 121).

Nas intervenções finais, criaram-se diversos dispositivos de relação e de jogo em que o espaço cênico era habitado e pertencia tanto aos espectadores quanto aos artistas. E era possível perceber várias camadas de público: os participantes dos grupos de investigação que ali assumiam a função de performers-artistas; os espectadores que foram especialmente assistir a intervenção; e os espectadores aleatórios - transeuntes e habitantes casuais dos espaços - que se surpreendiam ao verem-se imersos em uma intervenção artística. O gesto de cada pessoa, cada ponto de vista assumido, cada trajetória efetuada, cada pausa, bem como cada vestimenta, bolsa ou objeto que alguém carregava consigo, todos esses pequenos detalhes estavam ali expostos em uma mesma rede de relações e composições.

Agora o espaço pertence aos espectadores e a mim sem hierarquias. Meus objetos, as bolsas e os casacos deles; os comentários deles e minha sonoplastia; às vezes minha imobilidade e os movimentos deles, outras vezes meu movimento e a imobilidade deles. Tudo e todos espalhados sobre o chão, numa superfície infinita, na qual movemos silenciosamente, sem direção precisa, sem ordem definida. (Heathfield e Glendinning apud Lepecki, 2017, p. 145).

Cada intervenção era assim formada por esta rede de relações que se estabeleciam no espaço-tempo, com certa atenção ao sutil jogo entre o contemplar e o criar, de forma que uma variação da forma de perceber algo já se constituía como uma composição, bem como uma composição já se constituía como uma nova forma de percepção. Cada pessoa carregava em si este poder de contemplar e de criar, mesmo que através de um simples gesto, ou de um traço no espaço através do caminhar, ou de uma inclinação de cabeça que possibilitava reencontrar a experiência de uma visão encarnada. Não há aqui um olhar 
totalmente de fora, sem corpo, aéreo e distanciado, há pertencimento e imersão a partir de onde é possível assumir certo posicionamento e perceber os pontos de vista a partir de onde cada um vive sua situação e seu contexto.

El público queda incluido en la performance, implícito en el mismo acto de mostrar a partir de una experiencia en relación a un espacio y una situación de la que forma también parte. Con ello comienza un cuestionamiento radical de la relación de exterioridad del espectador que ha terminado transformando inevitablemente las formas de hacer teatro y entender como marco público de actuación.

Este modo de entender el hacer artístico abre un umbral de desestabilización e intercambio entre la obra y su entorno, entre la acción y el lugar en el que se hace, atravesado por una memoria y una historia, así como entre los distintos lenguajes artísticos, cuyo diálogo hasta ese momento había sido canalizado por la discusión sobre lo específico de cada uno de ellos. La performance no significó un nuevo estilo o poética, sino otro modo de entender y relacionarse con el espacio del arte en tanto que actividad. Este giro está motivado, no por una falta de atención en relación al entorno, sino al contrario, por una toma de conciencia acerca de la dimensión pública de este entorno. (Cornago, 2019, p. 23).

O questionamento dos espaços tradicionalmente utilizados pela dança e a busca por outras espacialidades revelam seu âmbito político ao proporem novas configurações espaço-temporais e novas formas de relações sociais. Assim, a experiência sensível e perceptiva do espectador em relação ao seu próprio corpo, ao espaço e às situações não está desvinculada de uma ação política, na medida em que possibilita a cada pessoa um maior reconhecimento de seus posicionamentos, a fim de compreendê-los, problematizá-los, vivenciá-los e quem sabe transformá-los. Segundo Rancière (2010), a arte não se revela política pelas representações das estruturas sociais, dos conflitos políticos ou das identidades sociais, étnicas ou sexuais, mas sim "pela maneira como configura um sensorium espaço-temporal que determina maneiras do estar junto ou separado, fora ou dentro, face a ou no meio de..." (Rancière, 2010, p. 46).

Ela é política enquanto recorta um determinado espaço ou um determinado tempo, enquanto os objetos com os quais ela povoa este espaço ou o ritmo que ela confere a esse tempo determinam uma forma de experiência específica, em conformidade ou em ruptura com outras: 
uma forma específica de visibilidade, uma modificação das relações entre formas sensíveis e regimes de significação, velocidades específicas, mas também e antes de mais nada formas de reunião ou de solidão. Porque a política, bem antes de ser o exercício de um poder ou uma luta pelo poder, é o recorte de um espaço específico de "ocupações comuns"; é o conflito para determinar os objetos que fazem ou não parte dessas ocupações, os sujeitos que participam ou não delas. (Rancière, 2010, p. 46).

\section{Considerações Finais}

O projeto Corpo e Paisagem, ao colocar em relação e diálogo cada performer, artista ou espectador com diferentes paisagens, evidenciou as características específicas de cada corpo e de cada contexto, com suas histórias de vida, suas origens, suas formas e seus fluxos. As criações realizadas no projeto surgiram da proposta de, sobretudo, perceber, sentir, olhar e escutar, com a devida atenção e cuidado, as vozes e os saberes que emanavam das pessoas e das paisagens, através da criação de dispositivos que ajudassem cada um de nós, participantes do projeto, a quebrarmos nossos vícios perceptivos e nos abrirmos para de fato olharmos para quem somos, para nossas relações, para onde estamos, de onde viemos e para o que cada contexto ou situação nos apresenta. As práticas instituídas não pretendiam criar algo genial ou inovador; estávamos mais atentos a de fato ouvirmos o que surgia de cada encontro, lugar ou situação, em uma atitude de aceitação das vulnerabilidades que, na verdade, revelava uma confiança em outro tipo de potência que poderia surgir a partir dessa entrega.

[...] el ámbito de lo público como territorio que pertenece a todos y a nadie, origen colectivo de una escena que nos demanda sobre todo responsabilidad y escucha, cuidado y atención, no solo con nosotros mismos, nuestras subjetividades y nuestra obra, sino también con la historia que nos precede, los lugares que habitamos, las personas que los transitan y los objetos que contienen esas memorias y esas historias. Estos elementos conforman un tejido sobre el que la escena recorta una ventana para convertirla en marco público de una actuación que se delimita y cobra sentido sobre ese horizonte de fondo continuamente desdibujado. (Cornago, 2019, p. 40). 
Assim, as criações de Corpo e Paisagem não eram exatamente para serem vistas ou assistidas a partir de um olhar distanciado do espectador, eram situações criadas que suscitavam um olhar encarnado, ou seja, uma visão permeada de todos os sentidos do corpo, uma visão situada, parcial e por isso mesmo detentora de saberes específicos que só são possíveis de serem atingidos na medida em que assumimos quem somos, onde estamos e a partir de onde experimentamos o mundo. O gesto ou a voz de cada participante, fosse ele espectador ou artista, tinha ali seu lugar e sua importância, revelando certo saber que encontra seu imenso valor justamente em sua limitação e vulnerabilidade. Essa junção de vozes, gestos, olhares parciais, que surgem e estão permeados de seus contextos, histórias e situações, formam aqui uma rede de conhecimentos e saberes que geram os sentidos ou significados, sempre inacabados, de cada obra artística criada.

Uma divisão dos sentidos, uma confusão entre voz e visão, mais do que ideias claras e distintas, torna-se a metáfora para a base do racional. Não buscamos os saberes comandados pelo falogocentrismo (saudades da presença da Palavra única e verdadeira) e pela visão incorpórea, mas aqueles comandados pela visão parcial e pela voz limitada. Não perseguimos a parcialidade em si mesma, mas pelas possibilidades de conexões e aberturas inesperadas que o conhecimento situado oferece. o único modo de encontrar uma visão mais ampla é estando em algum lugar em particular. [...]. Suas imagens não são produtos da escapatória ou da transcendência de limites, isto é, visões de cima, mas sim a junção de visões parciais e de vozes vacilantes numa posição coletiva de sujeito que promete uma visão de meios de corporificação finita continuada, de viver dentro de limites e contradições, isto é, visões desde algum lugar. (Haraway, 1995, p. 33).

\section{Referências}

ARDENNE, Paul. Un Arte Contextual. Creación artística en medio urbano, en situación, de intervención, de participación. Tradução: Françoise Mallier. Múrcia: Ad Literam, 2004.

BARDET, Marie. A Filosofia da Dança: um encontro entre dança e filosofia. Tradução: Regina Schöpke e Mauro Baladi. São Paulo: Martins Fontes - selo Martins, 2014. 
BESSE, Jean-Marc. Ver a Terra: seis ensaios sobre a paisagem e a geografia. Tradução: Vladimir Bartalini. São Paulo: Perspectiva, 2014.

CORNAGO, Óscar. La escena como marco público. Ejercicio de reflexión en tres tiempos. In: CORNAGO, Óscar; FERNANDES, Sílvia; GUIMARÃES, Julia (Org.). O Teatro como Experiência Pública. 1. Edição - São Paulo: Hucitec, 2019.

DARDEL, Eric. O Homem e a Terra: natureza da realidade geográfica. Tradução: Werther Holzer. São Paulo: Perspectiva, 2015.

DESGRANGES, Flávio. A Inversão da Olhadela: alterações no ato do espectador teatral. São Paulo: Hucitec, 2012.

GODARD, Hubert. Entrevista com Hubert Godard, por Suely Rolnik. In: ROLNIK, Suely (Org.). Lygia Clark, da obra ao acontecimento. Somos o molde. A você cabe o sopro. São Paulo: Pinacoteca do Estado, 2006.

HARAWAY, Donna. Saberes Localizados: a questão da ciência para o feminismo e o privilégio da perspectiva parcial. In: Cadernos Pagu n.5, Universidade de Campinas, 1995.

JARDIM, Juliana. Ensaios Ignorantes: nem cena nem aula. In: Org. CORNAGO, Óscar; FERNANDES, Sílvia; GUIMARÃES, Julia. O Teatro como Experiência Pública. $1^{a}$. Edição - São Paulo: Hucitec, 2019.

KWON, Miwon. Um Lugar após o Outro: anotações sobre site-specificity. Tradução: Jorge Menna Barreto. In: Arte e Ensaios n.17, 2008.

LEPECKI, André. Exaurir a Dança: performance e a política do movimento. Tradução: Pablo Assumpção Barros Costa. 1. Edição - São Paulo: Annablume, 2017.

LEPECKI, André. Planos de Composição. In: GREINER, Christine; SANTO, Cristina E.; SOBRAL, Sonia (Org.). Cartografia Rumos Itaú Cultural Dança 2009-2010: Criações e Conexões. São Paulo: Itaú Cultural, 2010.

RANCIĖRE, Jacques. O Espectador Emancipado. Tradução Ivone C. Benedetti. São Paulo: Editora WMF Martins Fontes, 2012.

RANCIĖRE, Jacques. Política da Arte. Tradução: Mônica Costa Netto. In: Urdimento ก. 15, 2010.

ROPA, Eugenia Casini. A Dança Urbana ou sobre a resiliência do espírito da dança. Tradução: Milton de Andrade. In: Urdimento n. 19, 2012.

SANTOS, Milton. A Natureza do Espaço: Técnica e Tempo, Razão e Emoção. 4ª. Edição - São Paulo: Editora da Universidade de São Paulo, 2017. 
TUAN, Yi-Fu. Topofilia: um estudo da percepção, atitudes e valores do meio ambiente. Tradução: Lívia de Oliveira. Londrina: Eduel, 2012.

VALVERDE, Isabel. Los encantos del paisaje y el malestar de la representación. In: RINCÓN, Daniel López del (Ed.). Naturalezas Mutantes. Del Bosco al Bioarte. VitoriaGasteiz: Sans Soleil Ediciones, 2017.

VELOSO, Veronica Gonçalves. Percorrer a cidade a pé: ações teatrais e performativas no contexto urbano. Tese Doutorado - Programa de Pós-graduação em Artes Cênicas - Escola de Comunicação e Artes / Universidade de São Paulo, 2017.

Recebido em: 30/06/2020

Aprovado em: 31/08/2020 